\title{
THE SEX RATIO OF HUMAN BIRTHS RELATED TO MATERNAL AGE*
}

BY

\author{
C. R. LOWE and THOMAS McKEOWN
}

From the Department of Social Medicine, University of Birmingham

Investigations of the sex ratio of human births have frequently included a brief reference to variations associated with the age of parents and with the order of birth. Numerous examinations of parental age have given conflicting results, and recent writers (Russell, 1936; Ciocco, 1938) have been unable to convince themselves that any consistent relationship exists between the sex ratio at birth and the age of the mother, the age of the father, or the difference in age of the two parents. More uniform results have been recorded for birth order, and in general it has been agreed that the sex ratio is higher for first born than for later born, and decreases as birth rank increases (Lewis and Lewis, 1906; Knibbs, 1917; Russell, 1936; Ciocco, 1938; Martin, 1943). Ciocco gives the explanation usually suggested for this observation: " that multiparae have a greater reproductive wastage than primiparae, and that the maternal organism is generally in better physiological condition before the first birth than after a series of pregnancies, especially if these occur at short intervals ". It is true of course that stillbirth rates are higher for all multiparae (considered together) than for primiparae; but stillbirth rates and sex ratios are both higher for first births than for those which immediately follow (second and third births). This objection appears not to have been considered.

Before proceeding to an examination of sex ratios at different maternal ages, we may consider briefly certain difficulties common to all investigations of the human sex ratio. For live births, stillbirths, and total births, ratios can be calculated from national statistics. For abortions earlier than the time when notification becomes effective (28 weeks in Great Britain) we have only such evidence as can be obtained from occasional examinations of aborted foetuses. On the question of greatest interest, the sex ratio at conception, we have no direct evidence, and must rely on conclusions drawn from the other data at our disposal.

We should also note the relationship of these sex ratios to one another. The sex ratio $\dagger$ of total births gives approximately the percentage of males among all

* This research was assisted by a grant from the Birmingham University Students' Social Services Fund.

+ In this communication the sex ratio is expressed as the percentage of males $\left(\frac{M}{\mathbf{M}+F} \times 100\right)$. The conventional method of expressing the ratio as the number of males per hundred females $\left(\frac{M}{F} \times 100\right)$ is misleading, as it gives an exaggerated impression of the masculine preponderance and does not lend itself to direct application of the usual statistical tests of significance. 
foetuses in the uterus at the 28th week of gestation; it differs from the ratio at conception only if the proportion of males aborted is not the same as the proportion conceived. Further, the sex ratio of live births differs from that of total births only if the proportion of males among stillbirths is not the same as among total births. Clearly, because of the relative numbers involved, differences between sex ratios of stillbirths and of total births will be reflected in much smaller differences between sex ratios of total births and of live births. And the same will also be true of the effect of sex ratios of abortions on differences between sex ratios of conceptions and of total births.

We now make use of data from the Annual Reports of the Registrar-General for Scotland, and for England and Wales, to examine the sex ratios of live births, stillbirths, and total births, at different maternal ages. Both sources provide the large numbers necessary for investigation of the small differences which are involved, and for the Scottish material ratios can be given separately for various causes of stillbirth. Unfortunately the data do not permit us to examine sex ratios in relation to birth order.

TABLE I

Sex Ratio of Births (Legitimate and Illegitimate combined) related to Maternal Age. (ENGLAND AND WALES, 1939-1947)

\begin{tabular}{|c|c|c|c|c|c|c|}
\hline \multirow{2}{*}{$\begin{array}{c}\text { Maternal Age } \\
\text { (years) }\end{array}$} & \multicolumn{2}{|c|}{ Live Births } & \multicolumn{2}{|c|}{ Stillbirths } & \multicolumn{2}{|c|}{ Total Births } \\
\hline & No. & $\%$ Males & No. & $\%$ Males & No. & $\%$ Males \\
\hline $\begin{array}{c}\text { Under } 20 \\
20-24 \\
25-29 \\
30-34 \\
35-39 \\
40 \text { and over } \\
\text { Not stated }\end{array}$ & $\begin{array}{r}230,267 \\
1,560,304 \\
1,881,163 \\
1,466,057 \\
840,822 \\
271,149 \\
24,707\end{array}$ & $\begin{array}{l}51 \cdot 72 \\
51 \cdot 58 \\
51 \cdot 45 \\
51 \cdot 44 \\
51 \cdot 26 \\
51 \cdot 16 \\
51 \cdot 80\end{array}$ & $\begin{array}{r}5,938 \\
36,256 \\
49,483 \\
47,509 \\
35,728 \\
16,565 \\
5,431\end{array}$ & $\begin{array}{l}51 \cdot 26 \\
53 \cdot 00 \\
53 \cdot 83 \\
54 \cdot 28 \\
54 \cdot 11 \\
54 \cdot 47 \\
54 \cdot 04\end{array}$ & $\begin{array}{r}236,205 \\
1,596,560 \\
1,930,646 \\
1,513,566 \\
876,550 \\
287,714 \\
30,138\end{array}$ & $\begin{array}{l}51 \cdot 70 \\
51 \cdot 61 \\
51 \cdot 51 \\
51 \cdot 53 \\
51 \cdot 38 \\
51 \cdot 35 \\
52 \cdot 20\end{array}$ \\
\hline All ages & $6,274,469$ & $51 \cdot 46$ & 196,910 & $53 \cdot 82$ & $6,471,379$ & $51 \cdot 53$ \\
\hline
\end{tabular}

TABLE II

Sex Ratio of Births (Legitimate and Illegitimate combined) related to Maternal Age. (SCOTLAND, 1939-1946)

\begin{tabular}{c|c|c|c|c|c|c}
\hline \multirow{2}{*}{$\begin{array}{c}\text { Maternal Age } \\
\text { (years) }\end{array}$} & No. & $\%$ Males & \multicolumn{2}{c|}{ Stillbirths } & \multicolumn{2}{c}{ Total Births } \\
\cline { 2 - 6 } & No. & $\%$ Males & No. & $\%$ Males \\
\hline Under 25* & 212,193 & $51 \cdot 47$ & 5,950 & $53 \cdot 14$ & 218,143 & $51 \cdot 52$ \\
$25-29$ & 213,019 & $51 \cdot 53$ & 6,996 & $53 \cdot 54$ & 220,015 & $51 \cdot 59$ \\
$30-34$ & 172,104 & $51 \cdot 30$ & 7,018 & $54 \cdot 56$ & 179,122 & $51 \cdot 43$ \\
$35-39$ & 102,981 & $51 \cdot 32$ & 5,601 & $54 \cdot 38$ & 108,582 & $51 \cdot 48$ \\
40 and over & 32,702 & $50 \cdot 56$ & 2,395 & $54 \cdot 53$ & 35,097 & $50 \cdot 83$ \\
Not stated & 2,683 & $51 \cdot 88$ & 101 & $62 \cdot 38$ & 2,784 & $52 \cdot 26$ \\
\hline All ages & 735,682 & $51 \cdot 39$ & 28,061 & $54 \cdot 00$ & 763,743 & $51 \cdot 48$ \\
\hline
\end{tabular}

* Numbers do not justify separation of births to mothers under 20 from births to mothers aged 20-24. 


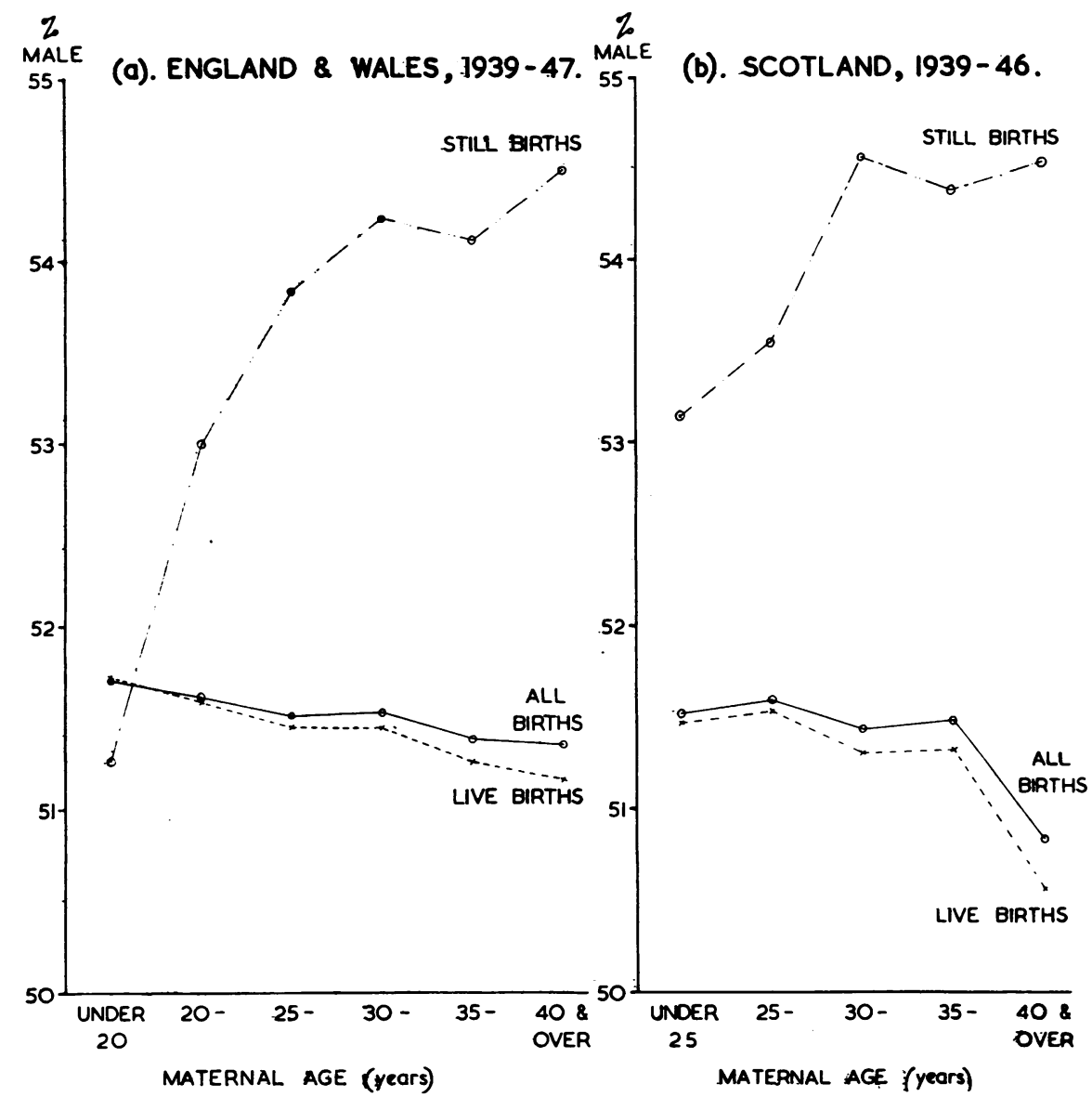

Fig. 1.-Sex Ratio of Births related to Maternal Age.

Sex Ratios of Total Births, Live Births, and Stillbirths, at Different Maternal Ages

Tables I and II give for England and Wales (1939-1947) and for Scotland (1939-1946), respectively, the sex ratios of live births, stillbirths, and total births, at different maternal ages (see also Fig. 1). Sex ratios of stillbirths increase with maternal age; sex ratios of live births and total births decrease. The age trends are exhibited by data from both sources, but are less regular in Scotland where numbers are much smaller than in England and Wales, and do not justify separation of births to mothers under 20 from births to mothers aged 20-24.

As indicated above, we must try to explain the observed changes in the ratios of total births and stillbirths, since together these determine the ratios of live births. For total births (England and Wales) the difference between the percentage of males in the lowest (under 20) and highest (40 and over) maternal age groups is $-0 \cdot 35 \pm 0 \cdot 14$. We have no direct evidence which explains this difference, but 
TABLE III

Sex Specific Stillbirth Rates related to Maternal Age. (England and Wales, 1939-1947)

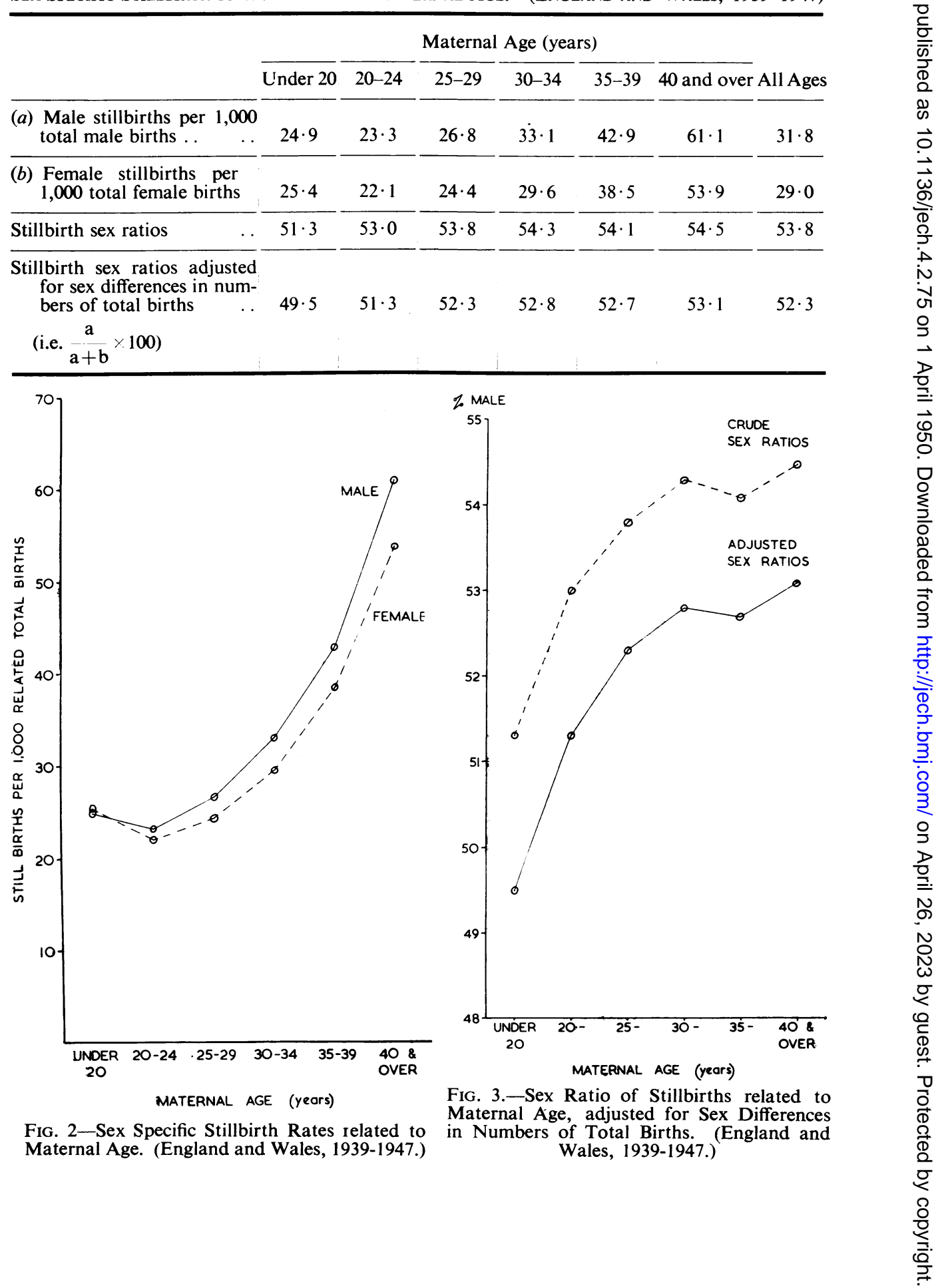


we may note that the difference in the sex ratios of live births between the same age groups is even greater $(-0 \cdot 56 \pm 0 \cdot 14)$. This difference between live births and total births results of course from the corresponding increase in the percentage of males among stillbirths $(+3 \cdot 21 \pm 0 \cdot 75)$. It therefore seems reasonable to suggest that the age trend of the sex ratio of total births may be explained by age differences in the sex ratios of abortions earlier than the 28th week (which are excluded from national statistics), and if this is the case the sex ratio of all births at conception would exhibit no age trend.

Our main problem, then, is to provide an explanation for the age trend of the sex ratio of stillbirths, but before proceeding to a more detailed examination of this question, we should note that the sex ratio of stillbirths, when expressed as the percentage of males among stillborn foetuses, is influenced by the sex ratio of related total births. In Table III stillbirth rates are given separately for males and females (see Fig. 2), and it will be seen that for mothers under 20 the death rate is actually higher for female than for male births, although the percentage of males among stillbirths is over 50 in this age group. Stillbirth sex ratios in each age group are considerably lower when calculated from the male and female stillbirth rates (Table III and Fig. 3), but show the same relationship to maternal age.

Sex Ratio of Stillbirths related to Cause and Maternal Age

One method of investigating the age trend of the sex ratio of stillbirths is to consider separately the different causes of stillbirths. The Annual Reports of the RegistrarGeneral for Scotland since 1939 provide data for this purpose, although numbers are small for examination of the differences noted above. Table IV (seealso Fig. $4 a$, overleaf)

TABLE IV

Sex Ratio of Stillbirths related to Cause and Maternal Age (Scotland, 1939-1946)

\begin{tabular}{|c|c|c|c|c|c|c|c|}
\hline \multirow{2}{*}{ Stillbirths attributed to } & \multicolumn{6}{|c|}{ Maternal Age (years) } & \multirow{2}{*}{ All Ages } \\
\hline & Under 25 & $25-29$ & $30-34$ & $35-39$ & 40 and over & Not stated & \\
\hline $\begin{array}{l}\text { Diseases in or accidents to } \\
\text { the mother }\end{array}$ & $\begin{array}{c}57 \cdot 5 \\
(1,400)^{*}\end{array}$ & $\begin{array}{c}56 \cdot 6 \\
(1,812)\end{array}$ & $\begin{array}{c}57 \cdot 2 \\
(1,872)\end{array}$ & $\begin{array}{c}57 \cdot 4 \\
(1,553)\end{array}$ & $\begin{array}{l}56 \cdot 4 \\
(713)\end{array}$ & $\begin{array}{l}63 \cdot 6 \\
(11)\end{array}$ & $\begin{array}{c}57 \cdot 1 \\
(7,361)\end{array}$ \\
\hline $\begin{array}{l}\text { Anomalies of foetus, plac- } \\
\text { enta, or cord }\end{array}$ & $\begin{array}{c}41 \cdot 0 \\
(1,502)\end{array}$ & $\begin{array}{c}42 \cdot 3 \\
(1,685)\end{array}$ & $\begin{array}{c}42 \cdot 9 \\
(1,609)\end{array}$ & $\begin{array}{c}42 \cdot 6 \\
(1,303)\end{array}$ & $\begin{array}{l}47 \cdot 6 \\
(515)\end{array}$ & $\begin{array}{r}44 \cdot 4 \\
(9)\end{array}$ & $\begin{array}{c}42 \cdot 6 \\
(6,623)\end{array}$ \\
\hline $\begin{array}{l}\text { Death of foetus by injury or } \\
\text { other cause }\end{array}$ & $\begin{array}{c}61 \cdot 3 \\
(1,622)\end{array}$ & $\begin{array}{c}58 \cdot 1 \\
(1,970)\end{array}$ & $\begin{array}{c}60 \cdot 6 \\
(2,062)\end{array}$ & $\begin{array}{c}59 \cdot 3 \\
(1,587)\end{array}$ & $\begin{array}{l}58 \cdot 9 \\
(637)\end{array}$ & $\begin{array}{l}55 \cdot 6 \\
(18)\end{array}$ & $\begin{array}{c}59 \cdot 7 \\
(7,896)\end{array}$ \\
\hline $\begin{array}{l}\text { Ill-defined and unknown } \\
\text { causes }\end{array}$ & $\begin{array}{c}52 \cdot 4 \\
(1,426)\end{array}$ & $\begin{array}{c}56 \cdot 5 \\
(1,529)\end{array}$ & $\begin{array}{c}55 \cdot 5 \\
(1,475)\end{array}$ & $\begin{array}{c}56 \cdot 9 \\
(1,158)\end{array}$ & $\begin{array}{l}53 \cdot 6 \\
(530)\end{array}$ & $\begin{array}{l}66 \cdot 7 \\
(63)\end{array}$ & $\begin{array}{c}55 \cdot 2 \\
(6,181)\end{array}$ \\
\hline All causes .. & $\begin{array}{r}53 \cdot 14 \\
(5,950)\end{array}$ & $\begin{array}{r}53 \cdot 54 \\
(6,996)\end{array}$ & $\begin{array}{r}54 \cdot 56 \\
(7,018)\end{array}$ & $\begin{array}{r}54 \cdot 38 \\
(5,601)\end{array}$ & $\begin{array}{r}54 \cdot 53 \\
(2,395)\end{array}$ & $\begin{array}{r}62 \cdot 4 \\
(101)\end{array}$ & $\begin{array}{r}54 \cdot 00 \\
(28,061)\end{array}$ \\
\hline $\begin{array}{c}\text { Sex ratios adjusted for } \\
\text { changing distribution of } \\
\text { causes } \dagger . .\end{array}$ & $53 \cdot 54$ & $53 \cdot 61$ & $54 \cdot 41$ & $54 \cdot 32$ & $54 \cdot 38$ & - & $54 \cdot 00$ \\
\hline
\end{tabular}

* Numbers of stillbirths (male and female) are given in brackets. † See text for discussion of method. 


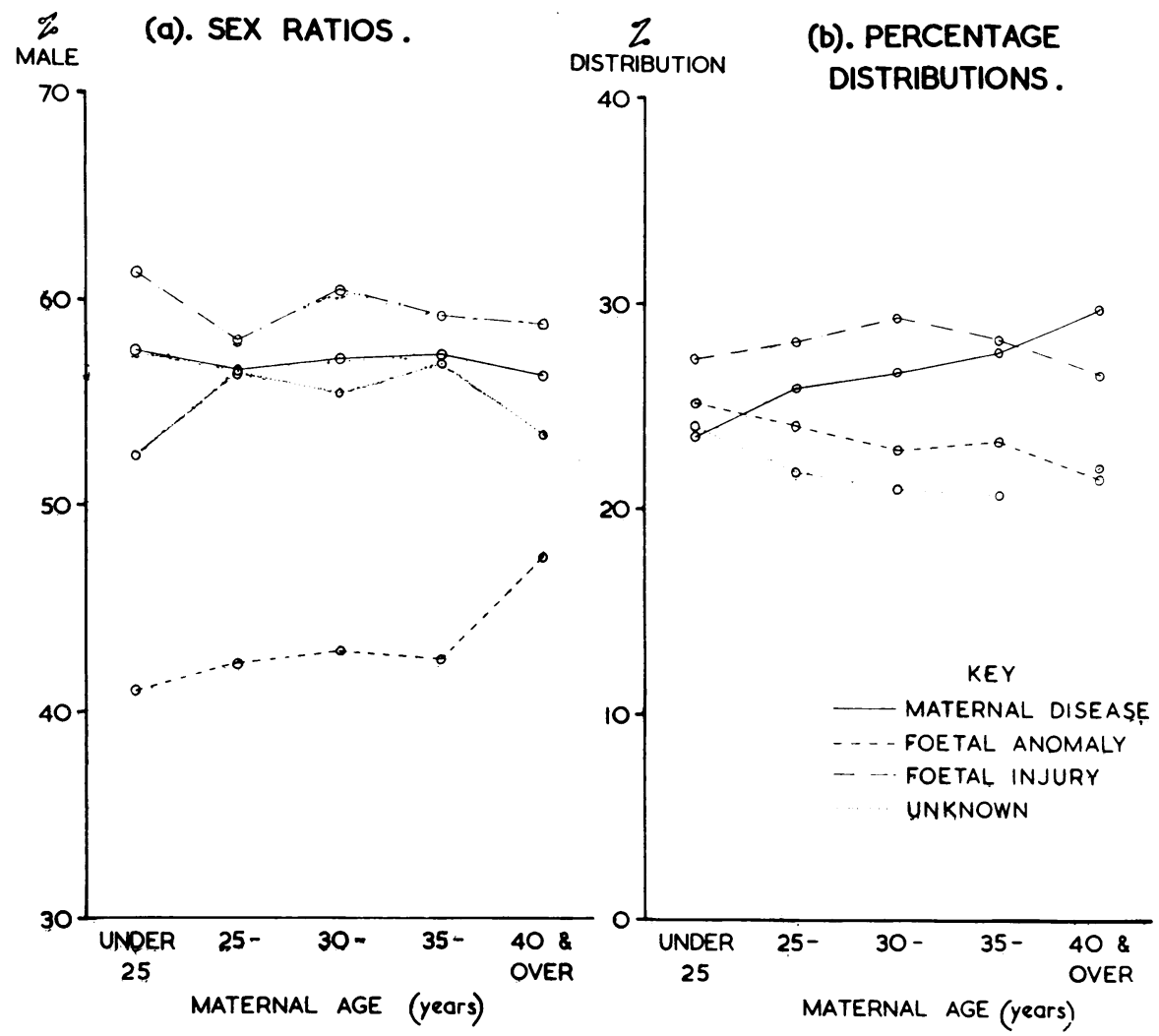

FIg. 4.-Sex Ratios and Percentage Distributions of Stillbirths related to Cause and to Maternal Age. (Scotland, 1939-1946.)

TABLE $V$

Percentage Distribution of Stillbirths by Cause at Different Maternal Ages (SCOTLAND, 1939-1946)

\begin{tabular}{|c|c|c|c|c|c|c|c|}
\hline \multirow{2}{*}{ Stillbirths attributed to } & \multicolumn{5}{|c|}{ Maternal Age (years) } & & \multirow{2}{*}{ - All Ages } \\
\hline & Under 25 & $25-29$ & $30-34$ & $35-39$ & 40 and over & Not stated & \\
\hline $\begin{array}{c}\text { Diseases in or accidents to } \\
\text { the mother }\end{array}$ & $23 \cdot 5$ & $25 \cdot 9$ & $26 \cdot 7$ & $27 \cdot 7$ & $29 \cdot 8$ & $10 \cdot 9$ & $26 \cdot 2$ \\
\hline $\begin{array}{c}\text { Anomalies of foetus, plac- } \\
\text { enta, or cord } \ldots\end{array}$ & $25 \cdot 2$ & $24 \cdot 1$ & $22 \cdot 9$ & $23 \cdot 3$ & $21 \cdot 5$ & $8 \cdot 9$ & $23 \cdot 6$ \\
\hline $\begin{array}{c}\text { Death of foetus by injury or } \\
\text { other cause }\end{array}$ & $27 \cdot 3$ & $28 \cdot 2$ & $29 \cdot 4$ & $28 \cdot 3$ & $26 \cdot 6$ & $17 \cdot 8$ & $28 \cdot 2$ \\
\hline \begin{tabular}{ccc} 
Ill-defined & and & \multicolumn{2}{c}{ unknown } \\
causes & $\ldots$ & $\ldots$
\end{tabular} & $24 \cdot 0$ & $21 \cdot 8$ & $21 \cdot 0$ & $20 \cdot 7$ & $22 \cdot 1$ & $62 \cdot 4$ & $22 \cdot 0$ \\
\hline All causes .. & $\begin{array}{l}100 \cdot 0 \\
(5,950)\end{array}$ & $\begin{array}{l}100 \cdot 0 \\
(6,996)\end{array}$ & $\begin{array}{l}100 \cdot 0 \\
(7,018)\end{array}$ & $\begin{array}{l}100 \cdot 0 \\
(5,601)\end{array}$ & $\begin{array}{l}100 \cdot 0 \\
(2,395)\end{array}$ & $\begin{array}{r}100 \cdot 0 \\
(101)\end{array}$ & $\begin{array}{c}100 \cdot 0 \\
(28,601)\end{array}$ \\
\hline
\end{tabular}


gives sex ratios in maternal age groups for the four main classes under which the Registrar-General lists stillbirths. Only one class (anomalies of foetus, placenta, or cord) shows any consistent relationship between sex ratio and maternal age, and even in this case the trend is not very convincing in view of the comparatively small numbers.

A possible explanation for the age trend of the sex ratio of stillbirths (all causes) is suggested in Table $\mathrm{V}$ (see also Fig. $4 b$ ), which gives by age group the percentages of stillbirths in the four main classes. As might be expected, these percentages change considerably with maternal age. For example, stillbirths due to " anomalies of foetus, placenta, or cord" (which have a sex ratio below 45 per cent.) are responsible for 25.2 per cent. of stillbirths of mothers under 25 , but for only 21.5 per cent. of stillbirths of mothers of 40 and over; stillbirths due to " diseases in or accidents to the mother" (which have a sex ratio above 55 per cent.) are responsible for $23 \cdot 5$ per cent. and $29 \cdot 8$ per cent. respectively of stillbirths of mothers in the same age groups. Since each of the four classes has a different sex ratio, it is evident that the trend in relation to maternal age is influenced by changing proportions as well as by changing sex ratios of stillbirths in each class.

These two effects can of course be separated. In Table IV, sex ratios have been calculated for stillbirths in each age group by applying the sex ratios for each cause at different age groups to the proportions at all ages. It will be observed that by keeping the proportions constant we eliminate a part of the variation with age.

None of the four classes so far considered is homogeneous, and each consists of a number of causes of stillbirth, each with its own sex ratio. It follows that the variation with age of the sex ratio of each class is also likely to be influenced by varying proportions of stillbirths due to different causes. We can most profitably consider the data in respect of " anomalies of foetus, placenta, or cord ".

In Table VI (see also Fig. $5 a$, overleaf) sex ratios are given separately for (a)

TABLE VI

Sex Ratios of Stillbirths due to Anomalies of Foetus, Placenta, or Cord related to Maternal Age. (SCOTland, 1939-1946)

\begin{tabular}{|c|c|c|c|c|c|c|c|}
\hline \multirow{2}{*}{ Stillbirths attributed to } & \multicolumn{6}{|c|}{ Maternal Age (years) } & \multirow{2}{*}{ All Ages } \\
\hline & Under 25 & $25-29$ & $30-34$ & $35-39$ & 40 and over & Not stated & \\
\hline (a) Anencephalus .. & $\begin{array}{l}27 \cdot 0 \\
(489)\end{array}$ & $\begin{array}{l}26 \cdot 3 \\
(509)\end{array}$ & $\begin{array}{l}25 \cdot 8 \\
(457)\end{array}$ & $\begin{array}{c}25 \cdot 9 \\
(347)\end{array}$ & $\begin{array}{l}29 \cdot 4 \\
(109)\end{array}$ & (1) & $\begin{array}{c}26 \cdot 5 \\
(1,912)\end{array}$ \\
\hline (b) Hydrocephalus & $\begin{array}{l}52 \cdot 5 \\
(236)\end{array}$ & $\begin{array}{l}51 \cdot 4 \\
(259)\end{array}$ & $\begin{array}{l}52 \cdot 5 \\
(263)\end{array}$ & $\begin{array}{l}47 \cdot 2 \\
(216)\end{array}$ & $\begin{array}{l}53 \cdot 1 \\
(81)\end{array}$ & (1) & $\begin{array}{c}51 \cdot 2 \\
(1,056)\end{array}$ \\
\hline (c) Other foetal defects & $\begin{array}{l}37 \cdot 0 \\
(395)\end{array}$ & $\begin{array}{l}41 \cdot 0 \\
(434)\end{array}$ & $\begin{array}{c}43 \cdot 9 \\
(430)\end{array}$ & $\begin{array}{l}44 \cdot 7 \\
(358)\end{array}$ & $\begin{array}{l}48 \cdot 3 \\
(151)\end{array}$ & (3) & $\begin{array}{c}42 \cdot 2 \\
(1,771)\end{array}$ \\
\hline $\begin{array}{l}\text { (d) Anomalies of placenta } \\
\text { or cord }\end{array}$ & $\begin{array}{l}56 \cdot 0 \\
(382)\end{array}$ & $\begin{array}{l}55 \cdot 3 \\
(483)\end{array}$ & $\begin{array}{l}53 \cdot 4 \\
(459)\end{array}$ & $\begin{array}{l}53 \cdot 1 \\
(382)\end{array}$ & $\begin{array}{l}55 \cdot 7 \\
(174)\end{array}$ & (4) & $\begin{array}{c}54 \cdot 5 \\
(1,884)\end{array}$ \\
\hline All causes .. & $\begin{array}{c}41 \cdot 0 \\
(1,502)\end{array}$ & $\begin{array}{c}42 \cdot 3 \\
(1,685)\end{array}$ & $\begin{array}{c}42 \cdot 9 \\
(1,609)\end{array}$ & $\begin{array}{c}42 \cdot 6 \\
(1,303)\end{array}$ & $\begin{array}{l}47 \cdot 6 \\
(515)\end{array}$ & (9) & $\begin{array}{c}42 \cdot 6 \\
(6,623)\end{array}$ \\
\hline
\end{tabular}




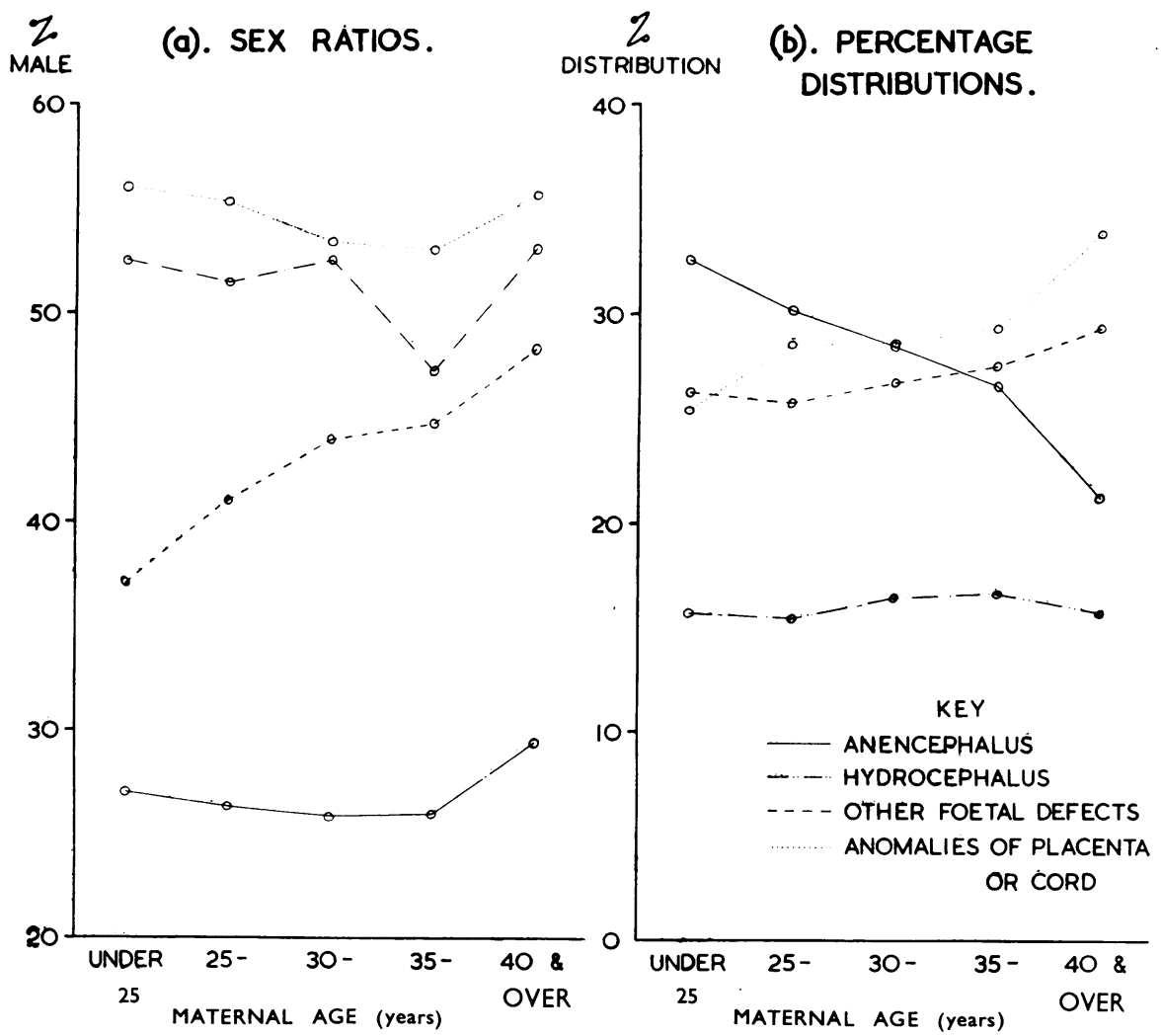

FIG. 5.-Sex Ratios and Percentage Distributions of Stillbirths due to Anomalies of Foetus, Placenta, or Cord, related to Maternal Age.

TABLE VII

Percentage Distributions of Stillbirths due to Anomalies of Foetus, Placenta, or Cord at Different Maternal Ages. (Scotland, 1939-1946)

\begin{tabular}{|c|c|c|c|c|c|c|c|}
\hline \multirow{2}{*}{ Stillbirths attributed to } & \multicolumn{6}{|c|}{ Maternal Age (years) } & \multirow{2}{*}{ All Ages } \\
\hline & Under 25 & $25-29$ & $30-34$ & $35-39$ & 40 and over & Not stated & \\
\hline (a) Anencephalus... & $\begin{array}{cc}. & 32 \cdot 6 \\
& (489)\end{array}$ & $\begin{array}{c}30 \cdot 2 \\
(509)\end{array}$ & $\begin{array}{c}28 \cdot 4 \\
(457)\end{array}$ & $\begin{array}{c}26 \cdot 6 \\
(347)\end{array}$ & $\begin{array}{l}21 \cdot 2 \\
(109)\end{array}$ & (1) & $\begin{array}{c}28 \cdot 9 \\
(1,912)\end{array}$ \\
\hline (b) Hydrocephalus & $\begin{array}{ll} & 15 \cdot 7 \\
& (236)\end{array}$ & $\begin{array}{l}15 \cdot 4 \\
(259)\end{array}$ & $\begin{array}{c}16 \cdot 4 \\
(263)\end{array}$ & $\begin{array}{l}16 \cdot 6 \\
(216)\end{array}$ & $\begin{array}{c}15 \cdot 7 \\
(81)\end{array}$ & (1) & $\begin{array}{c}15 \cdot 9 \\
(1,056)\end{array}$ \\
\hline (c) Other foetal defects & $\begin{array}{l}26 \cdot 3 \\
(395)\end{array}$ & $\begin{array}{l}25 \cdot 8 \\
(434)\end{array}$ & $\begin{array}{c}26 \cdot 7 \\
(430)\end{array}$ & $\begin{array}{c}27 \cdot 5 \\
(358)\end{array}$ & $\begin{array}{l}29 \cdot 3 \\
(151)\end{array}$ & (3) & $\begin{array}{c}26 \cdot 7 \\
(1,771)\end{array}$ \\
\hline $\begin{array}{c}\text { (d) Anomalies of placen } \\
\text { or cord }\end{array}$ & $\begin{array}{cc}\text { ta } & 25 \cdot 4 \\
\cdots & (382) \\
\end{array}$ & $\begin{array}{c}28 \cdot 6 \\
(483) \\
\end{array}$ & $\begin{array}{c}28 \cdot 5 \\
(459) \\
\end{array}$ & $\begin{array}{c}29 \cdot 3 \\
(382) \\
\end{array}$ & $\begin{array}{l}33 \cdot 8 \\
(174)\end{array}$ & (4) & $\begin{array}{c}28 \cdot 5 \\
(1,884)\end{array}$ \\
\hline All causes & $\begin{array}{c}100 \cdot 0 \\
(1,502)\end{array}$ & $\begin{array}{l}100 \cdot 0 \\
(1,685)\end{array}$ & $\begin{array}{l}100 \cdot 0 \\
(1,609)\end{array}$ & $\begin{array}{l}100 \cdot 0 \\
(1,303)\end{array}$ & $\begin{array}{c}100 \cdot 0 \\
(515)\end{array}$ & (9) & $\begin{array}{l}100 \cdot 0 \\
(6,623)\end{array}$ \\
\hline
\end{tabular}


anencephalus, $(b)$ hydrocephalus, $(c)$ other foetal defects, and $(d)$ anomalies of placenta or cord. In only one case $(c)$ is there evidence of a consistent age trend, and Table VII (see also Fig. $5 b$ ) again exhibits by age groups the varying proportions due to each cause. In this class, anencephalus, with a sex ratio of 26.5 per cent. for stillbirths at all ages, is responsible for 32.6 per cent. of -stillbirths of mothers under 25 , and for 21.2 per cent. of stillbirths of mothers over 40; " anomalies of placenta or cord ", with a sex ratio of 54.5 per cent., is responsible for 25.4 per cent. and 33.8 per cent. respectively of stillbirths in the same age groups. Clearly part of the age variation of the sex ratio of the class " anomalies of foetus, placenta, or cord" results from the changing proportions. And it should be noted that "other foetal defects", which exhibits an age trend, is a mixed group, in which changing proportions of individual causes may explain the observed variation.

In short, we have no evidence that the sex ratio of any single cause of stillbirth changes with maternal age, and we have good reason to suspect that changes in the proportions of stillbirths attributable to individual causes explain the slight but significant rise in the sex ratio with increasing maternal age.

\section{Discussion}

We should first note that in investigations of the association of the sex ratio with maternal age and order of birth, we are dealing with small differences for which only large numbers can be expected to give consistent results. In the data here examined age trends are quite definite, and there can be little doubt that the trend with parity, which is generally accepted, is even more conspicuous.

Recognizing that the sex ratios of stillbirths provide the explanation for the difference between ratios of live and total births, we have focused attention on stillbirths. We have observed that individual causes of stillbirth have different sex ratios, and that the proportionate contribution of each cause varies with maternal age. Indeed this may entirely explain the age trend of the sex ratio, since we have no evidence of age variation for any single cause which we can examine in substantial numbers.

But since the distinction between abortions and stillbirths is an arbitrary one which depends simply on the date of notification, it is quite certain that different causes of abortion have different sex ratios, and more than likely that the proportion attributable to each cause also varies with maternal age. If so, no further explanation is needed for the age trend of the sex ratio of total births, which may result from differential displacement of the sexes by abortions at different ages, and may be quite compatible with conception ratios which do not vary with maternal age.

These considerations suggest an explanation for the observed trend of the sex ratio in association with birth order, or indeed for a trend in association with any variable with which alterations may be anticipated in the composition of stillbirths. For example, among malformations of the central nervous system resulting in 
stillbirths or first-year deaths, risks of anencephalus (sex ratio 27 per cent.) and of spina bifida (sex ratio 43 per cent.) are more closely associated with parity than with maternal age; risk of hydrocephalus (sex ratio 51 per cent.) is more closely associated with maternal age than with parity (Record and McKeown, 1949). This will be reflected in changes in the sex ratio of stillbirths, with birth rank in the first two cases, and with maternal age in the third case. Naturally, as these two variables (age and birth rank) are highly correlated, large numbers of observations would be needed to separate their effects. ${ }^{*}$ We may recall that the father's age is also correlated with maternal age and parity, and it is hard to believe that changes reported in the sex ratio with paternal age are not simply the result of this correlation.

The main interest of these observations lies not in the slight differences of sex ratio associated with maternal age or parity, but in the fact that they direct attention to the significance of individual causes of stillbirth and abortion. In the past the high sex ratio of stillbirths has been accepted without sufficient consideration of the many factors by which it is modified. Indeed, since we cannot observe the sex ratio at conception, no question related to the sex ratio of human births is more important.

\section{SUMMARY}

(1) Data from the Annual Reports of the Registrar-General for England and Wales (1939-1947), and for Scotland (1939-1946), are used to show that:

(a) Sex ratios of total births and live births decrease with maternal age; sex ratios of stillbirths increase.

(b) The increase in the sex ratio of stillbirths with maternal age accounts for the difference between live births and total births; it is suggested that the decrease in the sex ratio of total births with maternal age may be explained by changes in the sex ratios of abortions earlier than the 28th week. If this is so, the sex ratio at conception would exhibit no trend with maternal age.

(2) Data from the Annual Reports of the Registrar-General for Scotland (1939-1946), which give the causes of stillbirth, are used to investigate the increase of the sex ratio with maternal age.

(a) The Registrar-General gives causes of stillbirth in four main classes. Each class has a different sex ratio, and changes in the sex ratio of all stillbirths with maternal age are in part attributable to changes in the relative proportions of these classes in each age group.

(b) None of the four classes is homogeneous, and each consists of a number of causes of stillbirth, each with its own sex ratio. Examination of " anomalies of foetus, placenta, or cord ", the class which exhibits the most definite age

\footnotetext{
* With the kind assistance of the Registrar-General, we obtained sex ratios of live births, stillbirths, and total births for England and Wales for 1948, by maternal age and parity. Numbers in this one year are not sufficiently large to give consistent results, and for this reason the data have not been included.
} 
trend, indicates that variation with age of the sex ratio of each class is also influenced by varying proportions of stillbirths due to individual causes within that class.

(c) In the data examined there is no evidence that the sex ratio of any single cause of stillbirth changes with maternal age. It is suggested that the reported trend of the sex ratio in association with birth order may also be explained by changes in the composition of stillbirths and abortions with parity.

Ciocco, A. (1938). Hum. Biol., 10, 36.

\section{REFERENCES}

Knibbs, G. H. (1917). "Census of the Commonwealth of Australia, 1911 ", Vol. I, Appendix A, Melbourne.

Lewis, C. J., and Lewis, J. N. (1905). “ “Natality and Fecundity.” Oliver and Boyd, Edinburgh.

Martin, W. J. (1943). Lancet, 2, 807.

Record, R. G., and McKeown, T. (1949). British Journal of Social Medicine, 3, 183.

Russell, W. T. (1936). J. Hyg., Camb., 36, 381. 